\title{
Increased exposure to community-based education and 'below the line' social marketing results in increased fruit and vegetable consumption
}

\author{
Colleen Glasson ${ }^{1, *}$, Kathy Chapman ${ }^{1}$, Tamara Wilson ${ }^{1}$, Kristi Gander ${ }^{1}$, \\ Clare Hughes ${ }^{1}$, Nayerra Hudson ${ }^{1}$ and Erica James ${ }^{2}$ \\ ${ }^{1}$ Cancer Council NSW, PO Box 572, Kings Cross, Sydney, NSW 1340, Australia: ${ }^{2}$ School of Medicine and \\ Public Health, University of Newcastle, Newcastle, New South Wales, Australia
}

Submitted 16 May 2012: Final revision received 10 April 2013: Accepted 8 May 2013: First published online 28 June 2013

\begin{abstract}
Objective: To determine if localised programmes that are successful in engaging the community can add value to larger fruit and vegetable mass-media campaigns by evaluating the results of the Eat It To Beat It programme.

Design: The Eat It To Beat It programme is a multi-strategy intervention that uses community-based education and 'below the line' social marketing to increase fruit and vegetable consumption in parents. This programme was evaluated by a controlled before-and-after study with repeat cross-sectional data collected via computer-assisted telephone interviews with 1403 parents before the intervention (2008) and 1401 following intervention delivery (2011).

Setting: The intervention area was the Hunter region and the control area was the New England region of New South Wales, Australia.

Subjects: Parents of primary school-aged children (Kindergarten to Year 6).

Results: The programme achieved improvements in knowledge of recommended intakes for fruit and vegetables and some positive changes in knowledge of serving size for vegetables. Exposure to the programme resulted in a net increase of 0.5 servings of fruit and vegetables daily for those who recalled the programme compared with those who did not $(P=0 \cdot 004)$. Increased intake of fruit and vegetables was significantly associated with increasing exposure to programme strategies.

Conclusions: The Eat It To Beat It programme demonstrates that an increase in consumption of fruit and vegetables can be achieved by programmes that build on the successes of larger mass-media and social-marketing campaigns. This suggests that funding for localised, community-based programmes should be increased.
\end{abstract}

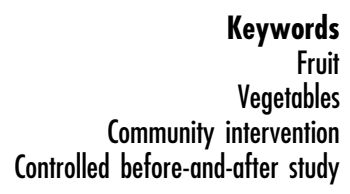

An adequate fruit and vegetable intake is protective against a number of chronic diseases including obesity, CHD and some cancers ${ }^{(1-4)}$ and significant health gains can be made from even small increases in fruit and vegetable intakes ${ }^{(5,6)}$. As daily fruit and vegetable consumption of adults is below the recommended levels of two servings of fruit and five servings of vegetables in Australia $^{(7,8)}$, more needs to be done to encourage an increase in consumption.

Internationally, several media and social-marketing interventions have resulted in improvements in fruit and vegetable intakes ${ }^{(9-12)}$. In Australia, the Go for $2 \& 5^{\circledR}$ fruit and vegetable campaign was conducted in Western Australia from 2002 to $2005^{(13)}$; the campaign launched nationally in $2005^{(14)}$, with New South Wales (NSW) launching its campaign in $2007^{(15)}$. Evaluations demonstrate that these campaigns can increase awareness and knowledge of fruit and vegetable recommendations and increased consumption of fruit and vegetables in Australian adults ${ }^{(13,15-17)}$.

Although many of these social-marketing campaigns have included different types and varying intensities of programme components such as accompanying websites, public relations events, publications and community or school-based activities, the main component of these programmes is usually a high-cost but short-lived media campaign with long off-air periods. Assessment of these campaigns shows that while short-term changes in consumption can be achieved in some cases, success is influenced by intensity of the message exposure, reach, timing and $\operatorname{cost}^{(12)}$ and sustained effects are difficult to maintain after the media campaign ends ${ }^{(18)}$. 
Therefore more needs to be done at a community level to promote, prolong and extend the messages to achieve additional, sustained behaviour change. Indeed, the Australian Government in its National Preventative Health Strategy recommends that social-marketing programmes to change lifestyle behaviours should 'Ensure mass media is accompanied by funded local programmes and skills development at the local level ${ }^{\text {(19) }}$.

Eat It To Beat It was a multi-strategy community-based intervention conducted by Cancer Council NSW from 2008 to 2010 in the Hunter region of NSW. The Hunter region is approximately $150 \mathrm{~km}$ north of Sydney and includes the regional centre of Newcastle with a population of approximately 540000 and a number of smaller outlying regional and rural communities. The programme aimed to increase the consumption of fruit and vegetables by parents of primary school-aged children by using localised community-based education and below the line' social marketing. For the purposes of the present study 'below the line' social marketing is defined as marketing via methods other than mass media ${ }^{(20)}$ and included information in school newsletters, cooking demonstrations, activities at community events and competitions. The strategies were designed to take a community engagement approach and complement existing mass-media campaigns.

The Eat It To Beat It programme supported the media messages from the NSW Go for $2 \& 5^{\circledR}$ campaign. This state-wide campaign included paid television, radio, cinema and print media advertisements, publications and web-based information, bus and supermarket trolley advertising, and supermarket demonstrations ${ }^{(15)}$. Most of the activity for this programme took place in the first half of 2007. The Eat It To Beat It programme also complemented the Good for Kids. Good for Life programme. This programme was conducted in the Hunter and New England regions of NSW continuously from 2007 to 2010 and used paid media to disseminate healthy lifestyle messages along with other strategies such as organisational change in local councils, schools, child-care centres, community service organisations, health services and sporting clubs to promote healthy eating and physical activity to children aged up to 15 years $^{(21)}$. The Good for Kids. Good for Life media campaign targeting vegetables was implemented in late 2009 and included television, radio and print media advertisements $^{(22)}$.

There are very few studies that isolate the effects of community-based education strategies and below the line marketing from the mass-media component of fruit and vegetable campaigns at a population level ${ }^{(18)}$. The present study uses the evaluation results of the Eat It To Beat It programme to investigate whether localised programmes that are successful in engaging the community can add value to larger fruit and vegetable mass-media campaigns.

\section{Methodology}

\section{The intervention}

\section{Theory for the intervention}

Parents of primary school-aged children (rather than children) were the focus of the Eat It To Beat It programme. The programme was developed following formative research to determine the motivators and barriers to fruit and vegetable consumption in this target group $^{(23)}$. These findings were integrated with a model proposed by Van Duyn et al. ${ }^{(24)}$ which used Social Cognitive Theory ${ }^{(25)}$, the PRECEDE-PROCEED model ${ }^{(26)}$ and the stage-of-change continuum ${ }^{(27,28)}$ to conceptualise the factors that influence healthy eating. Van Duyn et al.'s model suggests that focusing on factors such as knowledge, awareness, attitudes and perceived barriers would result in an increase in fruit and vegetable consumption $^{(24)}$.

\section{Strategies}

The programme strategies included: Fruit \& Veg \$ense, an education programme facilitated by trained community peer educators ${ }^{(29)}$; the Fruit \& Vegie Drive, a fruit and vegetable fundraiser box; Fruit 'n' Veg Month, a campaign for primary schools; shopping centre cooking/tasting demonstrations; and a communication strategy utilising free editorial in local print media generated through local community engagement activities, community service announcements and nutrition snippets for school newsletters. The programme maximised its resources by using volunteers to implement and administer some of the strategies and by negotiating significant free media.

\section{Study design}

Figure 1 shows how the current study operated in relation to other programmes during the same time frame. As it was not feasible to evaluate the programme using a randomised controlled trial for a number of methodological reasons ${ }^{(30,31)}$, the programme was evaluated by a controlled before-and-after study. The study was conducted according to the guidelines laid down in the Declaration of Helsinki and all procedures involving human subjects were approved by the Cancer Council NSW's Ethics Committee in October 2007 (approval number 226). Informed verbal consent was obtained from all participants.

\section{Data collection}

Data for the present repeat cross-sectional study were collected using computer-assisted telephone interviews with sampling via random digit dialling. The benchmark survey was conducted from 17 January to 27 February 2008, with the follow-up survey conducted from 20 January to 20 February 2011. The methodology for both waves was identical. 


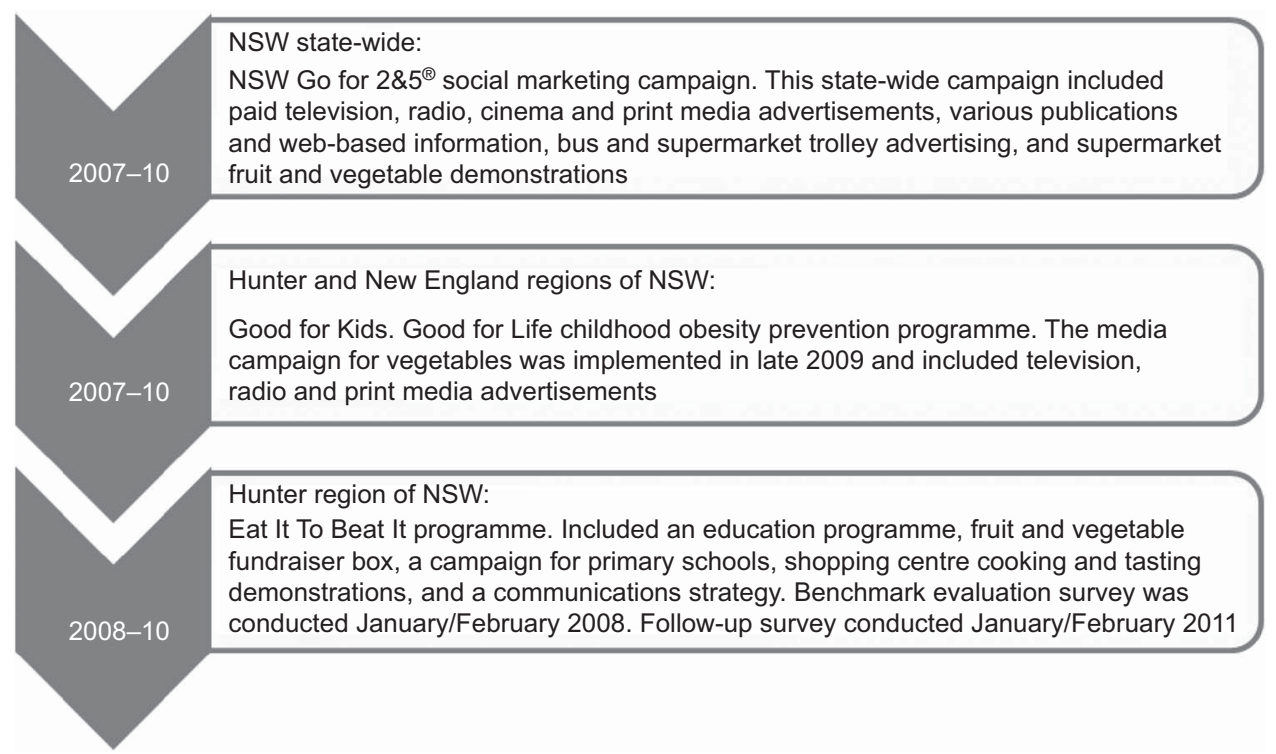

Fig. 1 Fruit and vegetable intervention programmes conducted concurrently in New South Wales (NSW), Australia from 2007 to 2010

\section{Participants}

The respondents were parents or carers of primary school-aged children who had primary responsibility for shopping and food preparation. Screening questions were used to identify in-scope respondents.

\section{Control group}

Various components of the NSW Go for $2 \& 5^{\circledR}$ campaign and the Good for Kids. Good for Life programme operated in both the Hunter and New England regions concurrently with the Eat It To Beat It programme (Hunter region only), see Fig. 1. To distinguish the effects of the Eat It To Beat It programme from both of these programmes, a control group was surveyed from the neighbouring New England area of NSW for both the benchmark and follow-up surveys.

\section{Measures}

The survey questionnaires were based on a review of the literature and piloted by the research team. To determine awareness of the programme, survey respondents were asked if they had seen anything from Cancer Council NSW or with the Eat It To Beat It logo encouraging them to buy more fruit and vegetables (prompted recall $)^{(13,15,16)}$ * To measure recognition of the programme elements, parents surveyed were prompted with a randomised list and asked whether they had seen or participated in a range of information, activities or events from Cancer Council NSW or with the Eat It To Beat It

\footnotetext{
* It should be noted the parents participating in the benchmark survey were asked this question in reference to the last few months, while those participating in the follow-up survey were asked about their exposure in 'the last couple of years'.
}

logo encouraging them to eat more fruit and vegetables in the last couple of years.

The study measures to compare benchmark with follow-up estimates included the following:

1. Knowledge of recommended intake was assessed by asking the respondents how many servings of fruit/ vegetables they thought they should eat every day to maintain good health. The open-ended responses (the number of servings needed) were categorised as either correct or incorrect.

2. Knowledge of recommended serving sizes was assessed by asking respondents what they thought one serving of fruit/vegetables equalled. Response choices were different cup measures ( $\frac{1}{2}$ cup, 1 cup, $1 \frac{1}{2}$ cups or none of the above for fruit; $\frac{1}{4}$ cup, $\frac{1}{2}$ cup, 1 cup or none of the above for cooked vegetables). Responses were dichotomised as correct or incorrect.

3. Fruit and vegetable consumption was measured by two short questions asking the parents 'How many servings of fruit/vegetables do you usually eat each day?' As examples of serving sizes were provided immediately before this question, consumption was based on the recommended serving size rather than the respondent's perception of serving size. These questions relied on self-report. Although they do not provide as accurate an estimate of absolute consumption as more detailed dietary assessment tools, they can effectively discriminate between groups with significantly different intakes of fruit and vegetables, rank individuals reasonably well and are widely accepted for use in population-based surveys ${ }^{(32-34)}$.

4. Age of respondents was collected in five discrete agerange categories. The mid-points of these age ranges 
(in single years) have been used for the coding of the continuous form of the variable in the Generalized Linear Modelling (GLM) procedure.

5. Approximate household annual income was collected in four discrete income categories. The mid-points of these income ranges (in units of \$AU 10000) have been used for the continuous form of the variable in the GLM procedure.

6. Education was collected in nine individual categories (primary school; year 10 or below; year 11 ; year 12 ; certificate at level 1 or 2 ; certificate at level 3 or 4 ; advanced diploma or diploma; bachelor or undergraduate degree; postgraduate degree, diploma or certificate). The mid-points of these categories (in years of education) have been used for the coding of the continuous form of the variable in the GLM procedure. The initial categories were further categorised as Year 12 or less, trade or certificate (technical education) and university undergraduate or postgraduate qualifications.

7. Exposure to programme strategies was measured as the total number of individual programme strategies that a parent claimed to have seen or participated in from the Eat It To Beat It programme. Participants were prompted with a randomised list of programme strategies. This variable was used as both a categorical variable (categories: 0, 1-5, 6-10, 11-15, 16-20) and as a continuous variable (coded using individual counts) in the GLM procedure.

\section{Sample size}

A sample size of 700 in both groups allowed for detection of differences of at least $7 \cdot 6 \%$ for a dichotomous variable, or a difference of $15 \%$ of a standard deviation for continuous variables, with $95 \%$ significance and $80 \%$ power. A sample size of 150 per group allowed for the detection of differences of 0.5 of a serving of fruit and vegetables ( 1 serving of fruit $=150 \mathrm{~g}$ and 1 serving of vegetables $=$ $75 \mathrm{~g}$ ), assuming a standard deviation of 1.6 servings $^{(35)}$, with $95 \%$ significance and $80 \%$ power.

\section{Analysis}

It was hypothesised that compared with the New England control group, parents from the target group in the Hunter region would report greater awareness of the programme, greater recognition of programme strategies and better knowledge of recommended intakes and serving sizes for fruit and vegetables. Furthermore, it was hypothesised that in the Hunter intervention area, there would be a dose-related response whereby an increased exposure to the number of different Eat It To Beat It programme elements would correspond with higher fruit and vegetable consumption.

Data were analysed using the statistical software package IBM SPSS Statistics version $20 \cdot 0$ for Windows.
Continuous and categorical outcome variables were compared by $t$ tests and $\chi^{2}$ tests, respectively. Parameter estimates for factors affecting fruit and vegetable intake (considered separately) were derived using GLM. A Poisson log-linear-type model was used with the categorical variables age, education level, income, knowledge of recommended fruit/vegetable intakes, knowledge of fruit/vegetable serving size and exposure to programme strategies. A separate model was derived using exposure to programme strategies as a continuous variable to examine the trend for this covariate. As log-transformed outcomes are used in the analysis, effects are reported in terms of proportionate changes in means rather than mean differences. Results were considered statistically significant at the $P<0.05$ level.

\section{Results}

\section{Response rate}

The benchmark survey resulted in 1403 completed interviews (695 surveys in the Hunter region, 708 in New England; $82 \%$ response rate). The follow-up survey resulted in 1401 surveys (700 surveys in the Hunter region, 701 in New England; 86\% response rate).

\section{Demographics}

Demographic characteristics of the sample are shown in Table 1. There were no significant differences in the demographic characteristics of the intervention and control groups except for approximate annual household income. The Hunter sample was skewed towards participants with higher incomes $(P<0 \cdot 0001)$ for both waves, but not higher levels of education. The sample characteristics fluctuated only slightly across both waves of the project.

\section{Awareness of programme strategies}

Recall of the category 'anything from the Cancer Council NSW or with the Eat It To Beat It logo encouraging them to buy more fruit and vegetables' (prompted recall) among parents in the Hunter region following the launch of the programme increased from $13 \%$ at benchmark to $28 \%$ at follow-up $(P<0 \cdot 0001)$. Similar increases were also seen among parents in New England between benchmark and follow-up (11\% at benchmark compared with $23 \%$ at follow-up, $P<0 \cdot 0001)$; however, there was a non-significant trend towards higher recall in the Hunter region. Seventy per cent of parents in the Hunter region reported seeing or participating in at least one strategy or activity of the Eat It To Beat It programme in 'the last couple of years'. This result was significantly higher than among control parents in New England (62\%,P=0.001). Table 2 compares the study groups' recognition of elements of the Eat It To Beat It programme at follow-up. 
Table 1 Demographic characteristics of the sample: parents with children of primary school age with primary responsibility for shopping and food preparation, Hunter and New England regions of New South Wales, Australia, 2008-2011

\begin{tabular}{|c|c|c|c|c|}
\hline \multirow[b]{2}{*}{ Characteristic } & \multicolumn{2}{|c|}{ Benchmark survey (2008) } & \multicolumn{2}{|c|}{ Follow-up survey (2011) } \\
\hline & $\begin{array}{c}\text { Hunter } \\
(n \text { 695) } \\
\%\end{array}$ & $\begin{array}{c}\text { New England } \\
(n 708) \\
\%\end{array}$ & $\begin{array}{c}\text { Hunter } \\
(n 700) \\
\%\end{array}$ & $\begin{array}{c}\text { New England } \\
(n 701) \\
\%\end{array}$ \\
\hline \multicolumn{5}{|l|}{ Respondent age } \\
\hline$\leq 24$ years & $1 \cdot 3$ & $1 \cdot 8$ & $0 \cdot 4$ & $1 \cdot 0$ \\
\hline $25-34$ years & $25 \cdot 8$ & $28 \cdot 0$ & $24 \cdot 6$ & $25 \cdot 7$ \\
\hline $35-44$ years & $58 \cdot 1$ & $54 \cdot 1$ & $55 \cdot 6$ & $54 \cdot 9$ \\
\hline $45-54$ years & $12 \cdot 9$ & $13 \cdot 4$ & $18 \cdot 1$ & $16 \cdot 5$ \\
\hline$\geq 55$ years & $1 \cdot 9$ & $2 \cdot 7$ & $1 \cdot 1$ & $1 \cdot 6$ \\
\hline \multicolumn{5}{|l|}{ Gender } \\
\hline Male & $14 \cdot 1$ & $11 \cdot 7$ & $16 \cdot 3$ & $14 \cdot 1$ \\
\hline Female & $85 \cdot 9$ & $88 \cdot 3$ & $83 \cdot 7$ & $85 \cdot 9$ \\
\hline \multicolumn{5}{|l|}{ Employment status } \\
\hline Full-time & $26 \cdot 5$ & $29 \cdot 9$ & $34 \cdot 7$ & $34 \cdot 4$ \\
\hline Part-time/casual & $37 \cdot 0$ & $36 \cdot 2$ & $35 \cdot 3$ & $35 \cdot 9$ \\
\hline Home duties & $29 \cdot 2$ & $28 \cdot 0$ & $22 \cdot 9$ & $22 \cdot 1$ \\
\hline Unemployed & $2 \cdot 9$ & $1 \cdot 8$ & $3 \cdot 9$ & $4 \cdot 1$ \\
\hline Student & $1 \cdot 7$ & $1 \cdot 6$ & $1 \cdot 3$ & $1 \cdot 4$ \\
\hline Age pension & $1 \cdot 3$ & $0 \cdot 3$ & $0 \cdot 4$ & $0 \cdot 0$ \\
\hline Pension other than age pension & $1 \cdot 4$ & $2 \cdot 0$ & $1 \cdot 3$ & 1.9 \\
\hline \multicolumn{5}{|l|}{ Highest level of education } \\
\hline Year 12 or less & $26 \cdot 8$ & $24 \cdot 3$ & $19 \cdot 1$ & $22 \cdot 8$ \\
\hline Trade or certificate (technical education) & $48 \cdot 6$ & $50 \cdot 4$ & $45 \cdot 9$ & $45 \cdot 1$ \\
\hline University undergraduate or postgraduate qualifications & $24 \cdot 4$ & $25 \cdot 0$ & $34 \cdot 4$ & $31 \cdot 7$ \\
\hline \multicolumn{5}{|l|}{ Approximate annual household income before tax } \\
\hline Less than $\$ A U 40000$ & $25 \cdot 0$ & $31 \cdot 8$ & $17 \cdot 5$ & $24 \cdot 1$ \\
\hline \$AU $40000-80000$ & $32 \cdot 9$ & $41 \cdot 1$ & $27 \cdot 8$ & $35 \cdot 2$ \\
\hline More than \$AU 80000 -less than \$AU 120000 & $42 \cdot 1$ & $27 \cdot 1$ & $32 \cdot 3$ & $23 \cdot 9$ \\
\hline$\$ A U 120000$ or over & $0 \cdot 0$ & $0 \cdot 0$ & $22 \cdot 4$ & $16 \cdot 8$ \\
\hline
\end{tabular}

${ }^{*}$ Denominator for each category may change due to missing values.

Table 2 Recognition of elements of the Eat It To Beat It programme at follow-up: parents with children of primary school age with primary responsibility for shopping and food preparation, Hunter and New England regions of New South Wales, Australia, 2011

\begin{tabular}{lccr}
\hline & $\begin{array}{c}\text { Hunter } \\
(n \text { 700) } \\
\text { Programme element }\end{array}$ & $\begin{array}{c}\text { New England } \\
\text { ( } n \text { 701) } \\
\%\end{array}$ & $P$ value \\
\hline Article in a school or other newsletter & 44 & 36 & $0 \cdot 004$ \\
Television community service announcement & 42 & 41 & $0 \cdot 328$ \\
Homework activity & 29 & 23 & $0 \cdot 031$ \\
Information sheet & 28 & 24 & 0.038 \\
Conversation with a friend or colleagues & 27 & 28 & 0.577 \\
Recipe cards & 24 & 19 & 0.070 \\
Fruit and vegetable boxes to raise money for the school/organisation & 21 & $<0.0001$ \\
An article in the local newspaper & 18 & 15 & 0.336 \\
Someone talking on local radio & 17 & 16 & 0.932 \\
A vegetable recipe demonstration & 14 & 8 & $<0.0001$ \\
Talk at a school assembly & 13 & 11 & 0.508 \\
Talk at a Transition to Kindergarten session & 13 & 11 & $0 \cdot 253$ \\
Competition promoting fruit and vegetables & 11 & 7 & 0.037 \\
Show bag of information & 10 & 6 & 0.002 \\
Fridge magnet & 10 & 8 & 0.319 \\
Cook \& Eat session held at a school & 8 & 6 & 0.500 \\
Website & 7 & 7 & 0.977 \\
An activity at a Cancer Council NSW event & 6 & 0.153 \\
Competition about families eating fruit and vegetables in local newspaper & 6 & 0.002 \\
A Fruit \& Veg \$ense session & 4 & 3 & 0.927 \\
\hline
\end{tabular}

\section{Knowledge of recommended fruit and vegetable intakes}

At the end of the intervention period, the proportion of Hunter parents who correctly stated that they should eat two servings of fruit each day increased significantly from $41 \%$ to $46 \%(P=0 \cdot 041)$ and the proportion who correctly stated they should eat five servings of vegetables each day increased significantly from $32 \%$ to $37 \%$ 
Table 3 Knowledge of recommended intakes and serving sizes at benchmark and follow-up: parents with children of primary school age with primary responsibility for shopping and food preparation, Hunter and New England regions of New South Wales, Australia, 2008-2011

\begin{tabular}{|c|c|c|c|c|c|c|}
\hline & \multicolumn{3}{|c|}{ Hunter } & \multicolumn{3}{|c|}{ New England } \\
\hline & $\begin{array}{l}\text { Benchmark } \\
\quad(n \text { 695) }\end{array}$ & $\begin{array}{l}\text { Follow-up } \\
(n 708)\end{array}$ & $P$ value & $\begin{array}{l}\text { Benchmark } \\
\quad(n 700)\end{array}$ & $\begin{array}{l}\text { Follow-up } \\
(n \text { 701) }\end{array}$ & $P$ value \\
\hline \multicolumn{7}{|l|}{ Fruit } \\
\hline \multicolumn{7}{|l|}{ Understanding of fruit servings recommended each day } \\
\hline$\%$ Correct & 41 & 46 & 0.041 & 42 & 45 & 0.419 \\
\hline \multicolumn{7}{|l|}{ Understanding of fruit serving size } \\
\hline$\%$ Correct & 54 & 55 & 0.818 & 55 & 58 & 0.308 \\
\hline \multicolumn{7}{|l|}{ Vegetables } \\
\hline \multicolumn{7}{|l|}{ Understanding of vegetable servings recommended each day } \\
\hline$\%$ Correct & 32 & 37 & 0.046 & 28 & 32 & $0 \cdot 199$ \\
\hline \multicolumn{7}{|l|}{ Understanding of vegetable serving size } \\
\hline$\%$ Correct & 34 & 39 & 0.073 & 34 & 34 & 0.883 \\
\hline
\end{tabular}

Table 4 Fruit and vegetable consumption at follow-up by exposure to the programme (prompted recall): parents with children of primary school age with primary responsibility for shopping and food preparation, Hunter and New England regions of New South Wales, Australia, 2011

\begin{tabular}{|c|c|c|c|c|c|c|c|c|c|}
\hline & \multicolumn{3}{|c|}{ Exposed } & \multicolumn{3}{|c|}{ Not exposed } & \multirow[b]{2}{*}{$\begin{array}{l}\text { Difference between exposed } \\
\text { and not exposed groups }\end{array}$} & \multirow[b]{2}{*}{$95 \% \mathrm{Cl}$} & \multirow[b]{2}{*}{ Difference $P$} \\
\hline & $\begin{array}{l}\text { Mean no. of } \\
\text { servings/d }\end{array}$ & & SD & $\begin{array}{l}\text { Mean no. of } \\
\text { servings/d }\end{array}$ & & SD & & & \\
\hline Hunter & & (n 199) & & & (n 498) & & & & \\
\hline \multirow{2}{*}{ New England } & & $(n$ 164) & $1 \cdot 90$ & & (n 534) & $2 \cdot 05$ & 0.48 & $0 \cdot 16,0 \cdot 82$ & 0.004 \\
\hline & $5 \cdot 04$ & & $2 \cdot 00$ & $4 \cdot 81$ & & $2 \cdot 09$ & 0.23 & $-0.13,0.59$ & $0 \cdot 210$ \\
\hline
\end{tabular}

$(P=0 \cdot 046 ;$ Table 3$)$. There were no corresponding significant increases in the New England control group.

\section{Knowledge of serving size}

There were no significant changes in the proportion of parents who could state the correct serving size for fruit in either the Hunter intervention group or in the New England control group (Table 3). There was a non-significant increase in the proportion of Hunter parents who could state the correct serving size for vegetables (34\% to 39\%, $P=0 \cdot 073$; Table 3).

\section{Consumption of fruit and vegetables}

For Hunter parents, the mean number of fruit and vegetable servings consumed fell by 0.3 servings/d; from 5.0 at benchmark to 4.7 servings/d at follow-up $(P=0.033)$. Similar results were also seen among parents in New England, where mean consumption fell from $5 \cdot 1$ to 4.9 servings/d $(P=0 \cdot 046)$. However, when only those parents who claimed to recall the programme (prompted recall) were considered, the mean number of servings of fruit and vegetables among parents in the Hunter region increased marginally, but not significantly, in comparison to benchmark (from $5 \cdot 0$ to $5 \cdot 1$ servings/d; Table 4). By contrast, the mean number of servings among parents who did not recall the programme decreased significantly (from 5.0 to 4.6 servings/d). This resulted in a net difference of 0.5 servings $/ \mathrm{d}(P=0.004)$. There were no corresponding differences found in the control group.

\section{Factors influencing fruit and vegetable consumption}

Table 5 shows that fruit intake was significantly associated with higher levels of education and increasing exposure to programme strategies. The fruit intake model with the continuous level of education variable suggests that every additional year of education results in a $5 \cdot 8 \%$ increase in the mean number of fruit servings consumed daily $\left(P_{\text {trend }}<0 \cdot 0001\right)$. The fruit intake model with the continuous exposure to programme strategies variable suggests that exposure to each additional programme strategy results in a $2 \cdot 0 \%$ increase in the mean number of fruit servings consumed daily $\left(P_{\text {trend }}=0 \cdot 007\right)$. Parents who had a correct knowledge of the recommended intakes for fruit were less likely to have higher intakes of fruit $(P<0 \cdot 0001)$.

Vegetable intake was significantly associated with age, higher levels of education and increasing levels of exposure to programme strategies. The vegetable intake model with the continuous level of age variable suggests that each additional year of age results in a $0.5 \%$ increase in the mean number of vegetable servings consumed daily $(P=0 \cdot 048)$. The vegetable intake model with the continuous level of education variable suggests that every additional year of education results in a $2 \cdot 0 \%$ increase in 


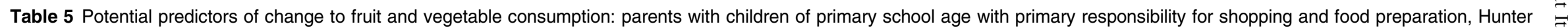
region of New South Wales, Australia, 2011 (relative difference percentages and 95\% confidence intervals)

\begin{tabular}{|c|c|c|c|c|c|c|c|c|}
\hline \multirow[b]{2}{*}{ Predictor } & \multicolumn{4}{|c|}{ Fruit } & \multicolumn{4}{|c|}{ Vegetables } \\
\hline & $\begin{array}{l}\text { Mean no. of } \\
\text { servings/d }\end{array}$ & $\begin{array}{l}\% \text { difference } \\
\text { in means }\end{array}$ & $95 \% \mathrm{Cl}$ & $P$ & $\begin{array}{l}\text { Mean no. of } \\
\text { servings/d }\end{array}$ & $\begin{array}{l}\% \text { difference } \\
\text { in means }\end{array}$ & $95 \% \mathrm{Cl}$ & $P$ \\
\hline \multicolumn{9}{|l|}{ Age } \\
\hline$\leq 24$ years & $2 \cdot 67$ & $211 \cdot 4$ & $27 \cdot 3,661 \cdot 3$ & 0.091 & $2 \cdot 00$ & $-29 \cdot 2$ & $-64 \cdot 2,40 \cdot 1$ & $0 \cdot 288$ \\
\hline $25-34$ years & $1 \cdot 62$ & $85 \cdot 3$ & $-4 \cdot 5,259 \cdot 4$ & & $2 \cdot 75$ & -3.9 & $-31 \cdot 4,34 \cdot 5$ & \\
\hline $35-44$ years & $1 \cdot 78$ & $95 \cdot 2$ & $1 \cdot 1,276 \cdot 7$ & & $3 \cdot 10$ & $2 \cdot 0$ & $-26 \cdot 9,42 \cdot 2$ & \\
\hline $45-54$ years & 1.89 & $106 \cdot 1$ & $6 \cdot 1,300 \cdot 1$ & & $3 \cdot 19$ & $6 \cdot 1$ & $-24 \cdot 3,48 \cdot 8$ & \\
\hline$\geq 55$ years & $1 \cdot 00$ & Ref. & & & $2 \cdot 86$ & Ref. & & \\
\hline Trend (per year increase) & & $0 \cdot 2$ & $-0 \cdot 6,0.9$ & 0.677 & & 0.5 & $0 \cdot 0,1 \cdot 0$ & 0.048 \\
\hline \multicolumn{9}{|l|}{ Income } \\
\hline Less than $\$ A U 40000$ & $1 \cdot 73$ & $9 \cdot 2$ & $-8 \cdot 6,30 \cdot 4$ & 0.799 & $2 \cdot 88$ & $0 \cdot 3$ & $-10 \cdot 7,12 \cdot 7$ & 0.570 \\
\hline \$AU $40000-80000$ & $1 \cdot 76$ & $4 \cdot 5$ & $-10 \cdot 4,22 \cdot 0$ & & $2 \cdot 83$ & $-4 \cdot 5$ & $-13 \cdot 7,5 \cdot 6$ & \\
\hline More than \$AU 80000 -less than \$AU 120000 & $1 \cdot 74$ & $2 \cdot 4$ & $-11 \cdot 3,18 \cdot 1$ & & $3 \cdot 18$ & 1.5 & $-7 \cdot 4,11 \cdot 3$ & \\
\hline \$AU 120000 or over & $1 \cdot 79$ & Ref. & & & $3 \cdot 12$ & Ref. & & \\
\hline Trend (per \$AU 10000 increase) & & $-0 \cdot 7$ & $-2 \cdot 1,0 \cdot 7$ & 0.327 & & 0.2 & $-0 \cdot 7,1 \cdot 12$ & 0.648 \\
\hline \multicolumn{9}{|l|}{ Highest education } \\
\hline Year 12 or less & 1.53 & $-26 \cdot 4$ & $-35 \cdot 7,-15 \cdot 8$ & $<0.0001$ & $2 \cdot 73$ & $-12 \cdot 6$ & $-19 \cdot 9,-4 \cdot 5$ & 0.003 \\
\hline Trade or certificate (technical education) & $1 \cdot 75$ & $-14 \cdot 6$ & $-25 \cdot 2,-2 \cdot 5$ & & $2 \cdot 84$ & $-12 \cdot 6$ & $-19 \cdot 9,-4 \cdot 5$ & \\
\hline $\begin{array}{l}\text { University undergraduate or postgraduate } \\
\text { qualifications }\end{array}$ & 1.99 & Ref. & & & $3 \cdot 45$ & Ref. & & \\
\hline Trend (per year of education increase) & & $5 \cdot 8$ & $3 \cdot 6,8 \cdot 1$ & $<0.0001$ & & $2 \cdot 0$ & $0 \cdot 6,3 \cdot 5$ & 0.005 \\
\hline \multicolumn{9}{|l|}{ Knowledge of recommended intakes } \\
\hline Correct & 1.52 & $-23 \cdot 7$ & $-31 \cdot 4,-15 \cdot 2$ & $<0.0001$ & $3 \cdot 79$ & $42 \cdot 5$ & $33 \cdot 1,52 \cdot 7$ & $<0.0001$ \\
\hline Incorrect & 1.96 & Ref. & & & $2 \cdot 56$ & Ref. & & \\
\hline \multicolumn{9}{|l|}{ Knowledge of serving size } \\
\hline Correct & $1 \cdot 72$ & $-2 \cdot 7$ & $-12 \cdot 2,7 \cdot 8$ & 0.598 & $3 \cdot 34$ & $7 \cdot 4$ & $0 \cdot 1,15 \cdot 3$ & 0.046 \\
\hline Incorrect & $1 \cdot 80$ & Ref. & & & $2 \cdot 81$ & Ref. & & \\
\hline \multicolumn{9}{|l|}{ Extent of exposure to programme strategies } \\
\hline 0 strategies & 1.69 & $4 \cdot 9$ & $-48 \cdot 6,114 \cdot 1$ & 0.025 & $2 \cdot 89$ & $-36 \cdot 7$ & $-56 \cdot 0,-8 \cdot 9$ & 0.020 \\
\hline $1-5$ strategies & 1.68 & $7 \cdot 9$ & $52 \cdot 9,119 \cdot 7$ & & $3 \cdot 07$ & $-31 \cdot 9$ & $-52 \cdot 6,-2 \cdot 2$ & \\
\hline $6-10$ strategies & $2 \cdot 09$ & $32 \cdot 0$ & $-35 \cdot 5,170 \cdot 3$ & & $3 \cdot 00$ & $-32 \cdot 7$ & $-53 \cdot 4,-2 \cdot 8$ & \\
\hline $11-15$ strategies & $1 \cdot 75$ & $11 \cdot 8$ & $-47 \cdot 6,138 \cdot 2$ & & $3 \cdot 33$ & $-22 \cdot 2$ & $-47 \cdot 6,15 \cdot 6$ & \\
\hline $16-20$ strategies & 1.50 & Ref. & & & $4 \cdot 25$ & Ref. & & \\
\hline Trend (per each additional strategy exposed to) & & $2 \cdot 0$ & $0.5,3 \cdot 4$ & 0.007 & & $1 \cdot 1$ & $0 \cdot 2,2 \cdot 1$ & 0.020 \\
\hline
\end{tabular}

Ref., reference category. 
the mean number of vegetable servings consumed daily $(P=0 \cdot 005)$. Similarly, the vegetable intake model with the continuous exposure to programme strategies variable suggests that exposure to each additional programme strategy results in a $1 \cdot 1 \%$ increase in the mean number of vegetable servings consumed daily $(P=0 \cdot 020)$. Parents who had a correct knowledge of the recommended intakes $(P<0 \cdot 0001)$ and serving sizes $(P=0.046)$ for vegetables were more likely to have higher intakes.

There were no significant associations for fruit or vegetables based on income.

\section{Discussion}

The results of the present study show that the Eat It To Beat It programme achieved improvements in fruit and vegetable intake in those parents exposed to the programme. Furthermore, the results demonstrate that increased intakes of fruit and vegetables were significantly associated with increasing exposure to programme strategies.

To achieve these results, the Eat It To Beat It programme maximised the use of programme funding by using volunteers to implement and administer some of the strategies and made optimal use of free media coverage that resulted from programme activities. However, the lowintensity nature of the programme means that the reach and dose of programme strategies achieved were lower than for a mass-media campaign. As a result, prompted recall of the Eat It To Beat It programme was low at $28 \%$ (an increase of 15\% from benchmark) compared with $92 \%$ for the Western Australian Go for $2 \& 5^{\circledR}$ campaign (no benchmark results reported) $^{(13)}$, 68\% (up 22\%) for the NSW Go for $2 \& 5^{\circledR}$ campaign $^{(15)}$ and $83 \%$ (up 59\%) for the national campaign ${ }^{(16)}$. Despite the low reach, parents in the Hunter area were more likely to have recalled or claimed to have participated in the main components of the Eat It To Beat It programme than those in the New England region.

Studies have shown that fruit and vegetable intake is significantly associated with knowledge of recommended intakes ${ }^{(36)}$. There were significant improvements in parents' knowledge of both fruit (an increase of $5 \%$ in the proportion of parents who stated they should eat two servings of fruit each day) and vegetable recommendations (an increase of $5 \%$ in the proportion of parents who stated they should eat five servings of vegetables each day) as a result of the Eat It To Beat It programme. These results compare favourably with no improvement reported in the national Go for $2 \& 5^{\circledR}$ campaign survey for fruit ${ }^{(16)}$ and an increase of $8 \%^{(16)}$ for vegetables. However, results from the GLM found that parents who had a correct knowledge of the recommended intakes for fruit were less likely to have higher intakes of fruit. Correct knowledge of the recommended servings for fruit is higher than for vegetables and therefore other factors such as eating fruit for its taste may mean that the correlation between correct knowledge of recommended intake for fruit and intake of fruit may not be as strong as it is for vegetables.

Increases in fruit and vegetable consumption as a result of large mass-media campaigns are of the order of $0 \cdot 4$ servings/d for the national Go for $2 \& 5^{\circledR}$ campaign $^{(16)}$ and 0.8 servings/d for the Western Australian Go for $2 \& 5^{\circledR}$ campaign $^{(13)}$. For the Eat It To Beat It programme, there was a significant decrease in consumption of fruit and vegetables in both the Hunter (decrease of 0.3 servings/d) and New England areas (decrease of 0.2 servings/d) at follow-up. However, this decrease in consumption must be considered in the light of other factors occurring during the intervention period. Perceived cost of fruit and vegetables has previously been reported as the second most important influence on food choice after taste ${ }^{(37)}$. Perceived cost was reported as the main barrier for both fruit and vegetables at follow-up in the present study. During the follow-up survey period there was a higher than expected increase in the cost of fruit and vegetables in the Hunter area due to significant flooding in agricultural regions of eastern Australia during 2010-11. This flooding was estimated to have reduced agricultural production by at least \$AU 500-600 million, with significant impacts on the production of fruit and vegetables immediately before the interview period ${ }^{(38)}$. Furthermore, a survey conducted by Cancer Council NSW found that the cost of a basket of eight common fruit and vegetables increased by more than $25 \%$ in real terms (i.e. adjusted for inflation) between December 2008 and January 2011 (Cancer Council NSW, unpublished results).

Despite this increase in the cost of fruit and vegetables, the decrease in consumption among parents in the Hunter region appears to be mitigated by exposure to the Eat It To Beat It programme and resulted in a significant difference of 0.5 servings of fruit and vegetables daily for those who recalled the programme compared with those who did not. Furthermore, there appears to be a doserelated response so that every additional programme strategy that a parent was exposed to resulted in an increase in consumption by parents.

These results emphasise the importance of local programmes that can engage the community on an ongoing basis to support and sustain the effects of larger mass-media campaigns. The funding available for health organisations to implement these programmes is typically meagre compared with funding available for large, massmedia type campaigns. Therefore, adequate funding for local programmes that deliver community-based education and 'below the line' social marketing needs to be provided to allow a greater reach and a higher dosage of programme strategies. Given the lack of controlled evaluations of smaller localised programmes, funding provided should be sufficient to include a good-quality evaluation component. 


\section{Limitations}

There was confusion between the brand and activities of the Eat It To Beat It programme and the two other major fruit and vegetable initiatives operating at the same time, leading to higher than expected levels of recall for the programme and its activities in the control population. Confusion between multiple programmes, activities and messaging has been noted in other studies ${ }^{(16,39,40)}$. In addition, there was some unavoidable contamination of the New England control area with some of the programme strategies such as Fruit 'n' Veg month that occurred across the state. Likewise, there may have been some cross-over of regional boundaries with some of the newspaper print articles about Eat It To Beat It activities.

The short questions used to determine fruit and vegetable consumption do not give as accurate an estimate of absolute intakes and this should be taken into account when interpreting these results.

Both the intervention and control sample populations were somewhat skewed towards tertiary-educated respondents and the intervention sample was skewed towards higher-income respondents for both waves. As a result, extrapolating these results to the overall population of parents of primary school-aged children should be done with caution.

\section{Conclusions}

Despite a modest programme reach, the Eat It To Beat It programme achieved improvements in knowledge of recommended intakes and some positive changes in knowledge of serving size for vegetables in its target population. While this has not translated into overall behaviour change across the population, exposure to the Eat It To Beat It programme appears to have positively influenced overall fruit and vegetable intake. The Eat It To Beat It programme demonstrates that additional gains in the modifiable, predisposing factors for consumption of fruit and vegetables and, to a limited extent, changes in actual consumption can be achieved by the implementation of community-based strategies that build on the successes of larger mass-media and social-marketing campaigns.

Furthermore, the results of the present study show the more activities parents were exposed to that promote and educate about fruit and vegetables, the greater the resulting increases in consumption. This suggests that funding for localised, community-based fruit and vegetable programmes should be increased.

\section{Acknowledgements}

Sources of funding: The Australian Government Department of Health and Ageing provided funding for project costs but had no influence on the design, analysis or reporting. Conflicts of interest: The authors have no conflicts of interest to declare. Authors' contributions: C.G. developed the methodology and the questionnaire and was responsible for data analysis and writing the manuscript. K.C. provided advice on the methodology and implementation of the research and assisted in writing the manuscript. T.W., K.G. and N.H. coordinated the implementation of the intervention and T.W., C.H. and N.H. assisted in writing the manuscript. E.J. provided advice on the methodology and assisted in writing the manuscript. Acknowledgements: The authors thank Christophe Lecathelinais for assistance with determining sample size, Sam Egger for assistance with statistical advice, the volunteers who assisted in the implementation of the programme and the participants.

\section{References}

1. Begg S, Vos T, Barker B et al. (2007) The Burden of Disease and Injury in Australia 2003. Canberra: AIHW.

2. Lichtenstein AH, Appel LJ, Brands M et al. (2006) Diet and lifestyle recommendations revision 2006: a scientific statement from the American Heart Association Nutrition Committee. Circulation 114, 82-96.

3. National Health and Medical Research Council (2013) Australian Dietary Guidelines. Canberra: NHMRC; available at http://www.nhmrc.gov.au/_files_nhmrc/publications/ attachments/n55_australian_dietary_guidelines_0.pdf

4. World Health Organization (2003) Diet, Nutrition and the Prevention of Chronic Disease. Report of a Joint WHO/FAO Expert Consultation. WHO Technical Report Series no. 916. Geneva: WHO.

5. Khaw K-T, Bingham S, Welch A et al. (2001) Relation between plasma ascorbic acid and mortality in men and women in EPIC-Norfolk prospective study: a prospective population study. Lancet 357, 657-663.

6. He FJ, Nowson CA, Lucas M et al. (2007) Increased consumption of fruit and vegetables is related to a reduced risk of coronary heart disease: meta-analysis of cohort studies. J Hum Hypertens 21, 717-728.

7. Australian Government Department of Health and Ageing (2008) Factsheet-Fruit and Vegetable Serves. http:// www.health.gov.au/internet/healthyactive/publishing.nsf/ Content/fact1 (accessed April 2012).

8. Centre for Epidemiology and Research (2010) 2009 Summary Report on Adult Health from the New South Wales Population Health Survey. http://www.health.nsw. gov.au/resources/publichealth/surveys/hsa_09summary.pdf (accessed April 2012).

9. Pomerleau J, Lock K, Knai C et al. (2005) Interventions designed to increase adult fruit and vegetable intake can be effective: a systematic review of the literature. J Nutr $\mathbf{1 3 5}$, 2486-2495.

10. Snyder LB, Hamilton MA, Mitchell EW et al. (2004) A metaanalysis of the effect of mediated health communication campaigns on behavior change in the United States. J Health Commun 9, Suppl. 1, 71-96.

11. Matson-Koffman DM, Brownstein JN, Neiner JA et al. (2005) A site-specific literature review of policy and environmental interventions that promote physical activity and nutrition for cardiovascular health: what works? Am J Health Promot 19, 167-193.

12. Brownson RC, Haire-Joshu D \& Luke DA (2006) Shaping the context of health: a review of environmental and policy approaches in the prevention of chronic diseases. Annu Rev Public Health 27, 341-370. 
13. Pollard CM, Miller MR, Daly AM et al. (2008) Increasing fruit and vegetable consumption: success of the Western Australian Go for 2\&5 campaign. Public Health Nutr 11, 314-320.

14. Australian Government Department of Health and Ageing (2008) Welcome to the Go for $2 \& 5^{\mathrm{TM}}$ Website. http:// www.health.gov.au/internet/healthyactive/publishing.nsf/ content/2and5 (accessed April 2012).

15. NSW Health, Cancer Institute of NSW (2007) Summary Report: Evaluation of the NSW Go for $2 E 5^{\circledR}$ Fruit and Vegetable Campaign. Sydney: NSW Health.

16. Elliott D \& Walker D (2007) Evaluation of the National Go for $\left.2 \varepsilon 5^{(}\right)$Campaign. Canberra: Australian Government Department of Health and Ageing; available at http:// www.health.gov.au/internet/healthyactive/publishing.nsf/ Content/EAED0B3283A8A1E2CA257259007CFC2D/\$File/ 2\&5-eval-jan06.pdf

17. Queensland Health (2010) The Health of Queenslanders 2010. Third Report of the Chief Health Officer Queensland. Brisbane: Queensland Health.

18. Wakefield MA, Loken B \& Hornik RC (2010) Use of mass media campaigns to change health behaviour. Lancet $\mathbf{3 7 6}$, 1261-1271.

19. Moodie AR, Daube M, Carnell K et al. (2009) Australia: the Healthiest Country by 2020. National Preventative Health Strategy - the Roadmap for Action. Canberra: Australian Government, Preventative Health Taskforce; available at http://www.preventativehealth.org.au

20. Carter SM (2003) Going below the line: creating transportable brands for Australia's dark market. Tob Control 12, Suppl. 3, iii87-iii94.

21. Hunter New England Area Health Service (2009) Good for Kids. Good for Life. About us. http://www.goodforkids. nsw.gov.au/About_Us (accessed April 2012).

22. Hunter New England Area Health Service (2009) Good For Kids. Good for Life. Vegies - Serve 'em up! Campaign. http://www.goodforkids.nsw.gov.au/Parents/Vegies_Serve_ em_up (accessed April 2012).

23. Eureka Strategic Research (2007) Influencing Food Purchasing Decisions. Sydney: Cancer Council NSW.

24. Van Duyn MA, Kristal AR, Dodd K et al. (2001) Association of awareness, intrapersonal and interpersonal factors, and stage of dietary change with fruit and vegetable consumption: a national survey. Am J Health Promot 16, 69-78.

25. Bandura A (1986) Social Foundations of Thought and Action: A Social Cognitive Theory. Englewood Cliffs, NJ: Prentice-Hall.

26. Green L \& Kreuter M (1991) Health Promotion Planning: An Educational and Environmental Approach, 2nd ed. Mountain View, CA: Mayfield Publishing Company.

27. Prochaska JO \& DiClemente CC (1983) Stages and processes of self-change of smoking: toward an integrative model of change. J Consult Clin Psychol 51, 390-395.
28. Ma J, Betts NM, Horacek T et al. (2003) Assessing stages of change for fruit and vegetable intake in young adults: a combination of traditional staging algorithms and food-frequency questionnaires. Health Educ Res 18, 224-236.

29. Glasson C, Chapman K, Gander K et al. (2012) The efficacy of a brief, peer-led nutrition education intervention in increasing fruit and vegetable consumption: a wait-list, community-based randomised controlled trial. Public Health Nutr 15, 1318-1326.

30. Atienza AA \& King AC (2002) Community-based health intervention trials: an overview of methodological issues. Epidemiol Rev 24, 72-79.

31. Merzel C \& D'Afflitti J (2003) Reconsidering communitybased health promotion: promise, performance, and potential. Am J Public Health 93, 557-574.

32. Coyne T, Ibiebele TI, McNaughton S et al. (2004) Evaluation of brief dietary questions to estimate vegetable and fruit consumption - using serum carotenoids and red-cell folate. Public Health Nutr 8, 298-308.

33. Greene GW, Fey-Yensan N, Padula C et al. (2004) Differences in psychosocial variables by stage of change for fruits and vegetables in older adults. J Am Diet Assoc 104, 1236-1243.

34. Marks GC (2001) Monitoring Food Habits in the Australian Population Using Short Questions. Canberra: Australian Food and Nutrition Monitoring Unit.

35. Glasson C, Chapman K \& James E (2010) Fruit and vegetables should be targeted separately in health promotion programmes: differences in consumption levels, barriers, knowledge and stages of readiness for change. Public Health Nutr 14, 694-701.

36. Shaikh AR, Yaroch AL, Nebeling L et al. (2008) Psychosocial predictors of fruit and vegetable consumption in adults a review of the literature. Am J Prev Med 34, 535-543.

37. Glanz K, Basil M, Maibach E et al. (1998) Why Americans eat what they do: taste, nutrition, cost, convenience, and weight control concerns as influences on food consumption. J Am Diet Assoc 98, 1118-1126.

38. Australian Bureau of Agricultural and Resource Economics and Sciences (2011) The Impact of Recent Flood Events on Commodities. Canberra: Australian Bureau of Agricultural and Resource Economics and Sciences.

39. Berry TR, Spence JC, Plotnikoff RC et al. (2009) A mixed methods evaluation of televised health promotion advertisements targeted at older adults. Eval Program Plann 32, 278-288.

40. Ashfield-Watt P, Welch A, Godward S et al. (2007) Effect of a pilot community intervention on fruit and vegetable intakes: use of FACET (Five-a-day Community Evaluation Tool). Public Health Nutr 10, 671-680. 